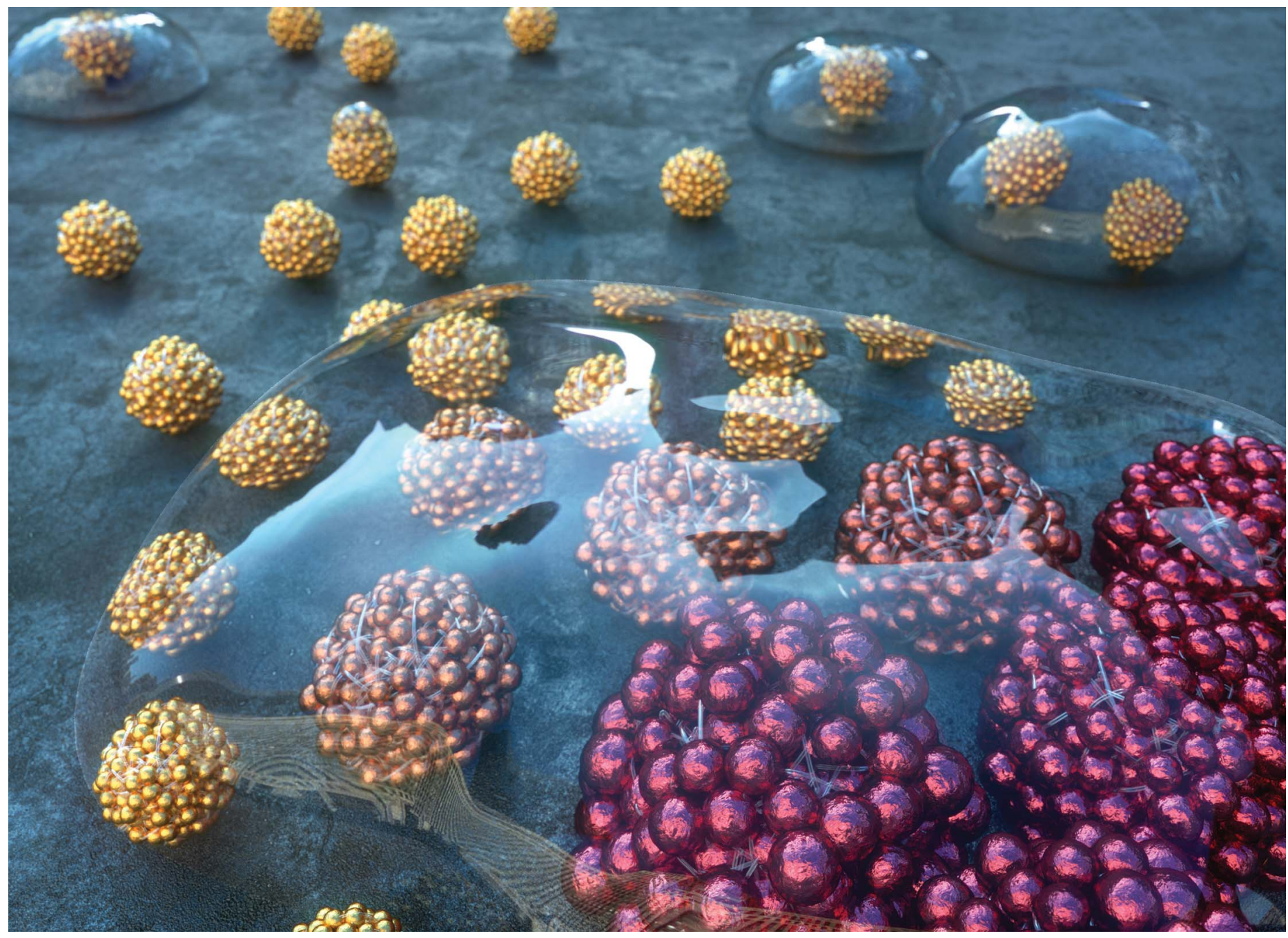

\section{Showcasing research from the Department of Chemistry Education, Seoul National University, Seoul, South Korea.}

Hygroscopy-induced nanoparticle reshuffling in ionic-gold-residue-stabilized gold suprananoparticles

Ionic precursors play a role in the generation of nanoparticles and influence their properties. The excess gold ions facilitate the formation of ultra-small gold nanoparticles and the further assembly of these small nanoparticles into suprananoparticles. The hygroscopic $\mathrm{Au}$ (III) residues in the suprananoparticles absorb moisture to form a micro-water pool and, subsequently, the nanoparticles are able to reshuffle to larger nanoparticles, which is used to detect the water content in organic solvents. Our results indicate that nanoparticle precursors may introduce additional characteristics and significantly change the properties of nanostructures.

\section{As featured in:}

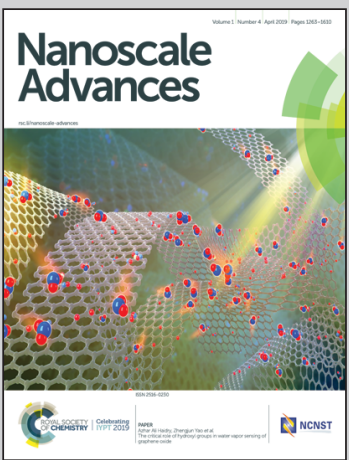

See Junhua Yu et al.

Nanoscale Adv., 2019, 1, 1331.

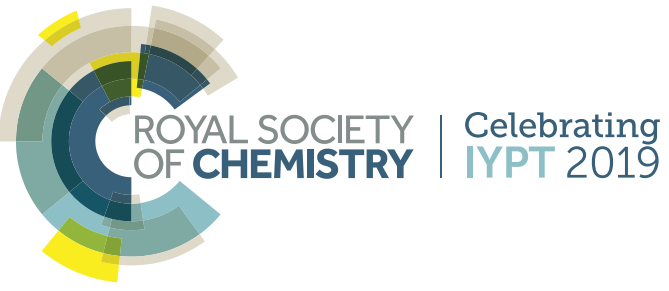


Check for updates

Cite this: Nanoscale Adv., 2019, 1, 1331

\title{
Hygroscopy-induced nanoparticle reshuffling in ionic-gold-residue-stabilized gold suprananoparticles $\uparrow$
}

\author{
Sungmoon Choi, (D) \$ Minyoung Lim, \$ Yanlu Zhao (D) and Junhua Yu (D)*
}

Polyethyleneimine (PEI)-stabilized gold nanoparticles were used as a model to understand the roles of ionic precursors in the formation of nanoparticles and the impact of their presence on the nanoparticle properties. The low availability of elemental gold and the stabilization of the just-generated gold nanoparticles by the excess gold ions contributed to the production of ultra-small nearly neutral gold nanoparticles, resulting in properties significantly different from those prepared by conventional methods. The cross-linking between gold ions/PEI/nanoparticles further led to the assembly of these small gold nanoparticles into suprananoparticles that were stable in water. The hygroscopic Au(III) residues in the suprananoparticles absorbed moisture to form a micro-water pool and the nanoparticles in the new aqueous solution reshuffled to generate larger nanoparticles, leading to significant changes in their optical properties. Such a phenomenon was formulated into a fast, sensitive and straightforward method for the detection of water content in organic solvents.

Received 23rd October 2018 Accepted 19th February 2019

DOI: $10.1039 / c 8 n a 00302 e$

rsc.li/nanoscale-advances resulting in the formation of cluster-like small nanoparticleaggregates (suprananoparticles). Moreover, the presence of gold ions in the solid state of the nanoparticles not only stabilized the gold nanoparticles, but they also acted as desiccants to absorb water molecules. The latter led to the formation of a nanoparticle suspension and induced the reshuffling of the nanoparticles, leading to a significant change in their morphology and photophysical properties.

\section{Results and discussion}

To investigate the role of gold ions during the formation of gold nanoparticles, the newly formed gold nanoparticles were stabilized with a stabilizer that does not neutralize the charge of the gold ions. Because the popular synthetic protocols of gold nanoparticles by citrate reduction in boiled water or borohydride reduction in the presence of alkanethiol likely involve the charged surface of the nanoparticles with a negative zeta potential, we used polyethyleneimine (PEI) as the reducing and stabilizing agent. ${ }^{5-7} \mathrm{PEI}$ has been used as a positive-charge carrier attached to gold nanoparticles for DNA/RNA delivery. ${ }^{8}$ It has also been applied as a reducing agent for the generation and simultaneous stabilization of gold nanoparticles. ${ }^{79}$ In this report, gold nanoparticles were generated from gold ions $\left(\mathrm{AuCl}_{4}^{-}, 0.34 \mathrm{mM}\right)$ and PEI (average $M_{\mathrm{n}} \sim 1200 \mathrm{Da}, 0.24 \mathrm{mM}$ ) with a PEI/Au(III) molar ratio of 1 : 1.4 in boiling water. The resulting gold nanoparticles were stable, with the characteristic plasmonic absorption of gold nanoparticles at $522 \mathrm{~nm}$ (Fig. 1A) and a narrow size distribution centred at $11 \mathrm{~nm}$ in diameter (Fig. 2A and B and ESI Fig. S1E $\dagger$ ). The properties of the above PEI-stabilized gold nanoparticles were
Department of Chemistry Education, Seoul National University, 1 Gwanak-Ro, Gwanak-Gu, Seoul 08826, South Korea.E-mail: junhua@snu.ac.kr

$\dagger$ Electronic supplementary information (ESI) available: Experimental details and TEM images. See DOI: 10.1039/c8na00302e

\$ These authors contributed equally to this work. 
A
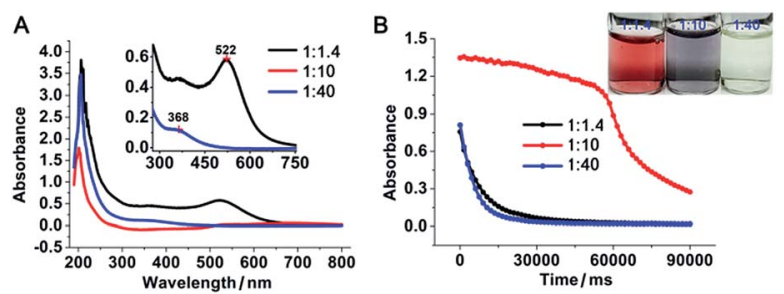

Fig. 1 Absorption and catalytic activity of gold nanoparticles prepared at a PEl/Au molar ratio of $1: 1.4,1: 10$ and $1: 40$. (A) Absorption spectra of the above gold nanoparticles. (B) Catalytic reduction of 4nitrophenol by these gold nanoparticles. Absorbance at the peak position for 4-nitrophenol $(400 \mathrm{~nm})$ as a function of time in the presence of the respective gold nanoparticles. In all cases, the concentrations of 4-nitrophenol and borohydride were $4.3 \times 10^{-3}$ and $6.3 \times 10^{-2} \mathrm{M}$, respectively. The concentration of the Au-based catalyst was $3.4 \times 10^{-4} \mathrm{M}$. Inset: photo of the solutions of the specific gold nanoparticles.

not significantly different from those of gold nanoparticles prepared by other methods. This was likely because all the gold ions were reduced completely and consequently formed nanoparticles. When the above PEI concentration was gradually decreased to a PEI/Au(III) molar ratio of $1: 10,1: 17$, and $1: 30$ without altering the gold ion concentration during the reduction process, an increasing number of nanoparticles fused to larger nanoparticles to form gold-wire networks $(1: 10$, Fig. 2C and D) and irregularly shaped plates $(1: 17$, Fig. $2 \mathrm{E}$ and $\mathrm{F})$, and further to form polygonal plates ( 1 : 30, Fig. $2 \mathrm{G}$ and $\mathrm{H}$ ). The colour of these nanoparticle solutions changed from vivid red to grey with obvious formation of nanoparticle agglomerates as the gold ratio increased (Fig. 1 and photo in Fig. 1B). The higher fusion rate between the nanoparticles in the high gold (low PEI) content solutions suggested that the surfaces of the gold nanoparticles were not capped well with protection groups so that these gold nanoparticles tended to grow larger to form gold nanoparticle networks as well as polygonal plates. ${ }^{\mathbf{1 0}}$

However, when the gold concentration was further increased to a $\mathrm{PEI} / \mathrm{Au}(\mathrm{III})$ molar ratio of $1: 40$, the gold nanoparticle solution became light yellow (Fig. 1B inset) and the characteristic plasmonic absorption of gold nanoparticles disappeared (Fig. 1A). Such an abrupt transition in their optical properties was due to a change in the nature of the nanoparticles. The TEM and SEM images of the high-gold-content gold nanoparticles at a lower resolution indicated that the gold nanoparticles were large with an average diameter of $40.8 \mathrm{~nm}$ (Fig. 2I, K and L). However, these "large nanoparticles" were spherical clusters (suprananoparticles) composed of many ultra-small gold nanoparticles that had an average diameter of $2.4 \mathrm{~nm}$ (Fig. 2J and $\mathrm{L}$ ). This was in line with the fact that the plasmonic absorption $(\sim 520 \mathrm{~nm})$ of nanoparticles less than $3 \mathrm{~nm}$ in diameter vanishes. ${ }^{\mathbf{1 1}}$ The $368 \mathrm{~nm}$ absorption in the absorption spectra was quite rarely assigned to the absorption of gold nanoparticles, but could be more likely ascribed to the absorption of the oxidized $\mathrm{PEI}^{\mathbf{1 2}}$ or $\mathrm{Au}_{m}{ }^{n+}$ clusters $(m>n)$ that either stayed on the surface of the gold nanoparticles or to the nanoparticle per se. ${ }^{\mathbf{1 3}}$ Further increasing the gold content to $1: 50$ or $1: 60$ in the above gold nanoparticle production protocol resulted in similar suprananoparticles to those observed at the 1:40 molar ratio (ESI Fig. S1†). Because the formation of the suprananoparticles might be due to the dewetting process during the TEM sample preparation, ${ }^{14}$ we examined their hydrodynamic radii with dynamic light scattering (DLS). The DLS results showed that there were four major components with a hydrodynamic diameter of $12 \pm 2,107 \pm 16$, $1010 \pm 340$, and $24100 \pm 3600 \mathrm{~nm}$ (ESI Fig. S2 $\dagger$ ); they were assigned to the free tiny gold nanoparticles, the suprananoparticles, larger aggregates of these suprananoparticles or polygonal plates, and agglomerates of these nanoparticles, respectively. This indicates that the suprananoparticles already formed before they were cast onto the TEM grids. The zeta potential of these suprananoparticles was only $0.4 \mathrm{mV}$, whereas the small gold nanoparticles had a zeta potential of $13 \mathrm{mV}$. Due to the nearly neutral surface of the nanoparticles that resulted in weaker repulsion but stronger van der Waals attraction among these nanoparticles, these nanoparticles tended to form aggregates. Moreover, the hydrogen-bonding between the PEI

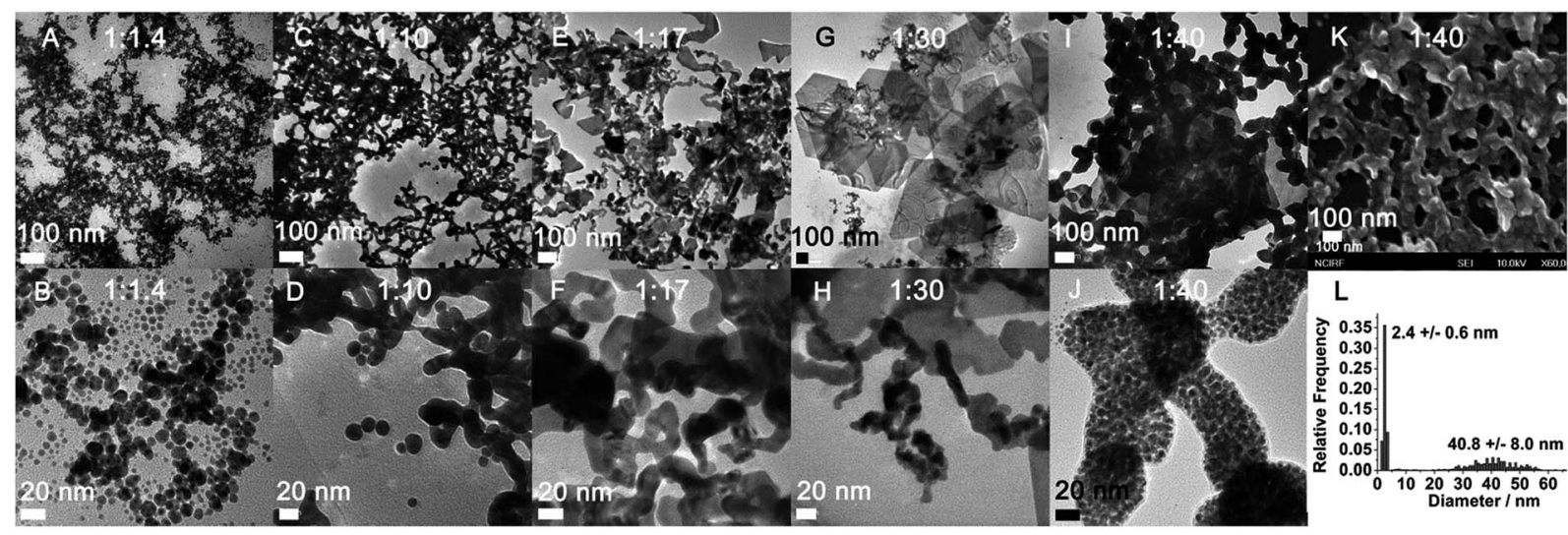

Fig. 2 Dependence of the gold nanoparticle generation on the PEI/Au(II) molar ratio. TEM images of gold nanoparticles at a PEI/Au(III) ratio of $1: 1.4(\mathrm{~A}, \mathrm{~B}), 1: 10(\mathrm{C}, \mathrm{D}), 1: 17(\mathrm{E}, \mathrm{F}), 1: 30(\mathrm{G}, \mathrm{H})$ and $1: 40(\mathrm{I}, \mathrm{J})$; SEM image (K) and size distribution (L) of nanoparticles at a PEI/Au(III) ratio of $1: 40$. The TEM images in the lower row were obtained at a higher resolution compared to those in the upper row. The gold concentration was kept at $3.4 \times 10^{-4} \mathrm{M}$. Scale bar: $100 \mathrm{~nm}(\mathrm{~A}, \mathrm{C}, \mathrm{E}, \mathrm{G}, \mathrm{I}$, and $\mathrm{K})$ and $20 \mathrm{~nm}(\mathrm{~B}, \mathrm{D}, \mathrm{F}, \mathrm{H}$, and J). 
networks and the coordinate bonding between the amino groups on the polymer chain and the gold ions also contributed to the formation of suprananoparticles. ${ }^{15,16}$ These gold suprananoparticles showed a similar catalytic activity for the reduction of 4-nitrophenol to 4-aminophenol to the small nanoparticles $(1: 1.4)$, but much better than the large nanoparticles $(1: 10) \cdot{ }^{17,18}$ As shown in Fig. 1B, the characteristic absorption of 4-nitrophenol $(400 \mathrm{~nm})$ decreased faster upon the catalysis by the small gold nanoparticles $(1: 1.4)$ and suprananoparticles $(1: 40)$, compared to that by the large nanoparticles $(1: 10)$. This suggests that the networks inside the suprananoparticles were quite permeable so that small molecules could diffuse into the core. Given the nanoparticle size of $2.4 \mathrm{~nm}$ in diameter, the pore in the spherical cluster (suprananoparticles) is about $2 \mathrm{~nm}$ in diameter, which allows the entry of small molecules into the inner part of the suprananoparticles. However, these suprananoparticles only illustrated moderate colloidal stability, fusing into larger nanoparticles within a day and then exhibiting the characteristic $520 \mathrm{~nm}$ absorption of gold nanoparticles (Fig. 3A and B). This was likely due to the lower charge density on the surface of these suprananoparticles. It has been reported that a higher sodium chloride concentration decreases the intra-chain repulsion of the PEI owing to the salt-screening effect and subsequently induces the contraction of the PEI chain. ${ }^{19}$ This may lower the levels of chain extension as well as the crosslinking between inter-PEI chains through hydrogen-bonding, and then causes the breakdown of the inter-PEI networks. Consequently, the suprananoparticles may disassemble in the presence of sodium chloride. As expected, no suprananoparticles were detected by TEM after the addition of sodium chloride $(150 \mathrm{mM})$ to the suprananoparticle solution, but no change in its absorption spectrum was observed (Fig. 3C and $\mathrm{D}$ ). Instead, the sodium chloride significantly delayed the
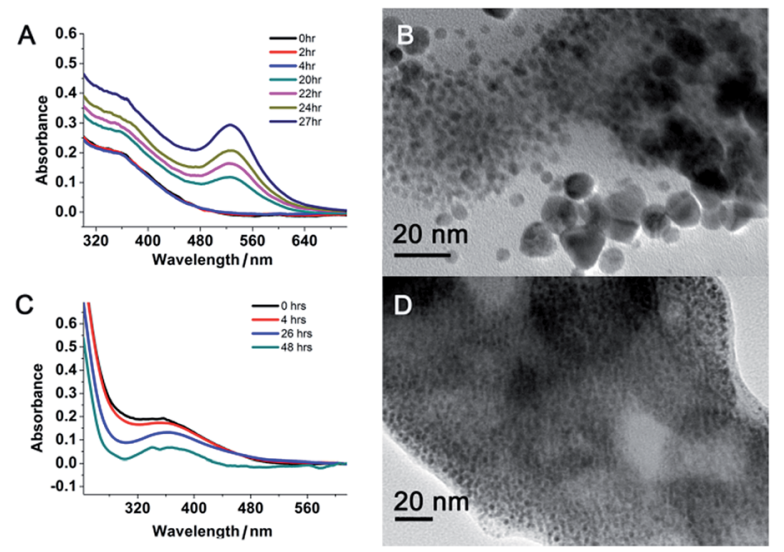

Fig. 3 Colloidal stability of the gold suprananoparticles prepared at a PEI/Au(III) molar ratio of $1: 40$. Time-dependent absorption spectra (A) and TEM image of the suprananoparticles after $27 \mathrm{~h}$ in water (B). Same sample but in the presence of sodium chloride $(150 \mathrm{mM})$. Timedependent absorption spectra (C) did not show the occurrence of the plasmonic absorption of the large gold nanoparticles at $520 \mathrm{~nm}$. However, the TEM image of the solution after $48 \mathrm{~h}$ in water (D) did not show any suprananoparticles but ultra-small nanoparticles. Scale bar, $20 \mathrm{~nm}$. transformation of the small nanoparticles into larger gold nanoparticles, as seen in the absorption spectra (Fig. 3C).

The PEI networks may contribute to the formation of nanoparticle clusters, but did not control the size of an individual gold nanoparticle. With a $\mathrm{PEI} / \mathrm{HAuCl}_{4}$ mass ratio of $1: 1$ in DMF, larger PEI molecules $\left(M_{\mathrm{n}} \sim 25 \mathrm{kDa}\right)$ stabilized and encapsulated multiple gold nanoparticles in PEI polymer shells. ${ }^{20}$ That reaction was equivalent to our protocol with a PEI/ Au molar ratio of $1: 1.4$. The sizes of the nanoparticles in these two reactions were similar but there were two major differences. (1) No obvious polymer shells were formed in our experiment because the polymer chain used in our protocol was too short. ${ }^{20}$ (2) The resulting PEI suprastructure of gold nanoparticles in the previous report was not stable in water. In our subsequent experiments, with less PEI and more gold content, we successfully obtained stable suprananoparticles in aqueous solution. The key to such an improvement was the excess of gold ions. As the number of PEI molecules decreased, the reducing power of PEI depleted, leading to the accumulation of $\mathrm{Au}$ (III) or $\mathrm{Au}(\mathrm{I})$ in the solution. Usually, a metal cluster can be further stabilized by capping the cluster with metal ions. ${ }^{21}$ Partially charged $\mathrm{Au}^{\delta+}$ species have also been found on the surface of citrate-anionstabilized gold nanoparticles. ${ }^{22}$ Therefore, in our case, it was more likely that these gold ions stayed on or even bonded to the surface of the newly formed gold nanoparticles, which were further stabilized by coordination with the amino groups on the PEI chains ${ }^{23}$ resulting in thermodynamically stable nanoparticles. Both the low level of reduced elemental gold and the outstanding stability of these ion-capping nanoparticles contributed to the generation of these ultra-small nanoparticles, as shown in Fig. 2J. To verify the above hypothesis, the XPS spectrum of the suprananoparticles was obtained. It clearly showed that the suprananoparticles consisted of $90 \%$ elemental gold, $5 \% \mathrm{Au}(\mathrm{I}$ ), and $5 \% \mathrm{Au}(\mathrm{III})$ (Fig. 4A). Meanwhile, the excess gold ions formed complexes with PEI chains to build crosslinked networks between these nanoparticles, resulting in gold suprananoparticles with excellent stability in water.

Interestingly, the freeze-dried gold suprananoparticles for the XPS test were light yellow powders. Once the powders were re-suspended in water, the suprananoparticles were restored without changes in their optical properties. However, such powders were extremely sensitive to moisture in the air. When exposed to air at a relative humidity of $50 \%$ at $25{ }^{\circ} \mathrm{C}$, the yellow powders changed to black within an hour but retained the
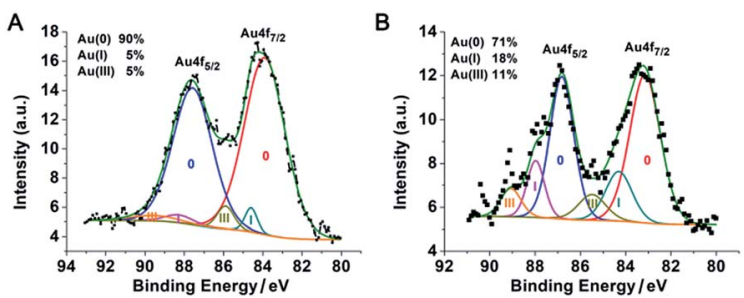

Fig. 4 XPS spectra of the suprananoparticles prepared at a PEI/Au(III) molar ratio of $1: 40$. More elemental gold was oxidized after the colour of the lyophilised gold suprananoparticles turned from yellow (A) to black (B). 
yellow colour in a desiccator for a month. It was highly possible that gold nanoparticles consisting of the suprananoparticles changed to larger nanoparticles because the freeze-dried gold nanoparticles (PEI/Au(III) molar ratio of $1: 1.4,11 \mathrm{~nm}$ in diameter) were also black, but it may be difficult for the solid gold suprananoparticles to proceed through such a dramatic change in the solid phase. However, the hygroscopic Au(III) residues in the suprananoparticles may absorb moisture to form a micro-water pool and subsequently the nanoparticles freely defused to meet their counterparts (Scheme 1) and then fused to larger nanoparticles. Such a phenomenon was recorded with a camera on an optical microscope. Right after the yellow powders were exposed to air on a coverslip, the yellow powders had started to absorb moisture; the granules of gold powders on the coverslip looked like they were surrounded by a thin layer of liquid (Fig. 5A). Within $40 \mathrm{~min}$, these gold granules had merged into a liquid film (Fig. 5B) and then the film became dark brown in $80 \mathrm{~min}$ (Fig. 5C). A detailed video (Fig. 5E and ESI Video-1 $\dagger$ ) showed that the granules absorbed water, grew larger, and finally merged into a larger film in $300 \mathrm{~s}$. Meanwhile, the colour of the water pools became darker. Such excellent hygroscopic capability was only exhibited by the suprananoparticles. The black powder of the freeze-dried gold nanoparticles (PEI/Au(III) molar ratio of $1: 1.4,11 \mathrm{~nm}$ in diameter) did not change its morphology at all in two hours when exposed to the above conditions (Fig. 5D and ESI Video$2 \dagger)$. These images/videos were consistent with our previous claim that the suprananoparticle powders absorbed water to form a micro-water pool and then nanoparticle-reshuffling occurred in the aqueous solution. Such reshuffling was concentration-dependent. It was much slower in dilute aqueous solution (taking place in $24 \mathrm{~h}$ ) but much faster in the above water pools. Moreover, the colour change of the gold species was simply a consequence of the fusion of smaller nanoparticles to form larger ones (ESI Fig. S3†), but was not because of the generation of more nanoparticles. XPS of these black gold powders suggests that more elemental gold was oxidized to $\mathrm{Au}(\mathrm{I})$ (18\%) and $\mathrm{Au}(\mathrm{III})$ (11\%), as shown in Fig. 4B. This shows that the ultra-small gold nanoparticles are relatively less

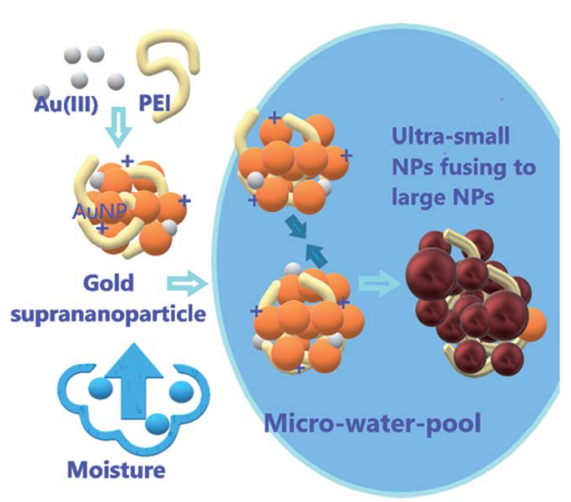

Scheme 1 Schematic showing hygroscopy-induced nanoparticle reshuffling. Gold ions in the suprananoparticles absorb moisture to form a micro-water-pool in which suprananoparticles reshuffle to form larger nanoparticles.

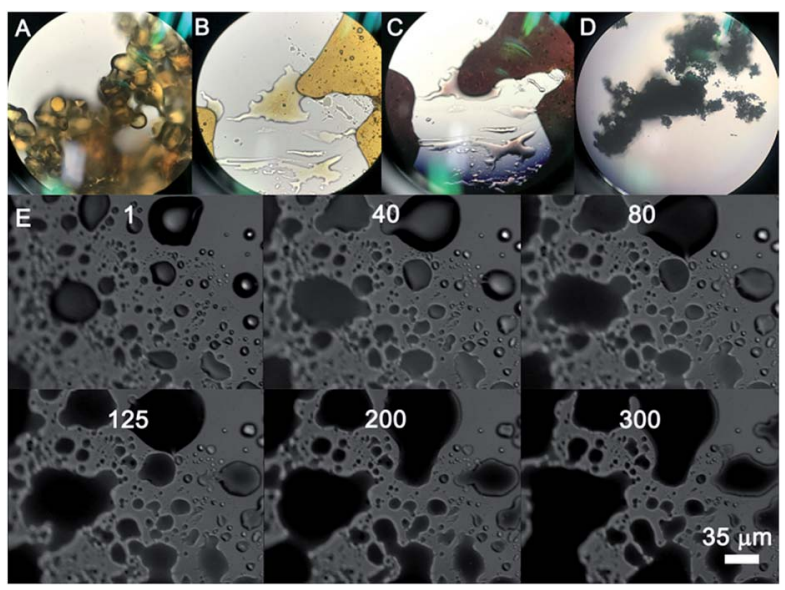

Fig. 5 Hygroscopic effect of the suprananoparticles. Photos of lyophilised suprananoparticles on a glass coverslip taken by using a colour camera in situ (A), after 40 min (B) and after 80 min (C) from an eyepiece of a microscope with a $20 \times$ objective under white light irradiation. They showed that the gold granules immersed in the newly formed water pool and the yellow gold species become dark brown. Such a process was recorded with a CCD camera on the same microscope, as shown in the screenshots of the video clip (E). The numbers in (E) stand for the time in seconds the lyophilised suprananoparticles were exposed to air. A photo of the lyophilised large gold nanoparticles (PEI/Au(III) molar ratio of $1: 1.4)$, taken $2 \mathrm{~h}$ after exposure to air showing no hygroscopic effect (D). Scale bar: $35 \mu \mathrm{m}$.

thermodynamically stable. ${ }^{24}$ While they were oxidized, these gold nanoparticles merged into larger gold nanoparticles that displayed different photophysical properties. The $\mathrm{Au} 4 \mathrm{ff}_{7 / 2}$ binding energy for the $\mathrm{Au}(0)$ component in the suprananoparticles was $83.9 \mathrm{eV}, 0.1 \mathrm{eV}$ shifted from that of gold foil $(84.0 \mathrm{eV}) .{ }^{25}$ Upon aggregation, the gold suprananoparticles grew larger and their binding energy decreased to $83.2 \mathrm{eV}$, in line with the fact that the larger the gold nanoparticles, the lower the binding energy. ${ }^{26}$ It is possible that the $\mathrm{Au}^{+}$binds to the surface of the gold nanoparticle with a binding energy of $84.5 \mathrm{eV}$ for $\mathrm{Au}(\mathrm{I})$, lower than the expected value of $85.2 \mathrm{eV}$ for $\mathrm{Au}^{+}$ions. ${ }^{22,27}$ The $\mathrm{Au} 4 \mathrm{f}_{7 / 2}$ binding energy for the $\mathrm{Au}(\mathrm{I})$ component in the suprananoparticles was $84.6 \mathrm{eV}$, suggesting the possible bonding between $\mathrm{Au}^{+}$and the gold nanoparticles. However, we cannot exclude the possible presence of organometallic $\mathrm{Au}(\mathrm{I})$ in the gold suprananoparticles.

The sensitivity of the gold suprananoparticles to moisture inspired us to apply the suprananoparticle as a water indicator. The main methods for water content detection in organic solvents have been based on an impedance tester, ${ }^{28}$ spectrometry, ${ }^{29,30}$ chromatography, ${ }^{31}$ and electrochemistry. ${ }^{32}$ Our approach may be an alternative to the above methods and presented a fast and straightforward detection of water content in organic solvents. Alcohols in which the suprananoparticles can dissolve should be avoided. The yellow suprananoparticle powders can be immersed in most organic solvents such as toluene, chloroform, acetonitrile and cyclohexane, in which the suprananoparticles were insoluble. The water in the solvent was extracted to the suprananoparticles, which formed water pools and subsequently the suprananoparticles reshuffled to generate 
large and black gold nanoparticles. As shown in Fig. 6A, the gold suprananoparticles detected as low as $0.01 \%$ water content in toluene within an hour, which is among the best detection limits reported. The higher the water concentration, the darker the gold suprananoparticles became. This method could be fast as well. The change in the colour of the gold suprananoparticles could be observed $20 \mathrm{~min}$ after the immersion of the gold suprananoparticles in the solvent (Fig. 6B). Moreover, the gold suprananoparticles can be a sensitive marker in solvents: no water in the solvent, no change in the colour. Once water dissolves in the solvent, the colour of the gold suprananoparticles will change to black. We are still working on minimizing the gold used for water detection while maximizing the signal from the optical change of the nanoparticles.

\section{Experimental}

\section{Synthesis of PEI-AuNPs at a PEI/Au(III) molar ratio of $1: \boldsymbol{x}$}

PEI solution $(2.4 \mathrm{mM}, 840 / x \mu \mathrm{L})$ was added dropwise into preheated gold(III) chloride trihydrate solution $(0.34 \mathrm{mM}, 6 \mathrm{~mL})$ with stirring in the dark for $5 \mathrm{~min}$ at $75{ }^{\circ} \mathrm{C}$. After cooling down for $60 \mathrm{~min}$ in the dark, (600-840/x) $\mu \mathrm{L}$ PEI stock solution (2.4 $\mathrm{mM}$ ) was added, followed by stirring for $1 \mathrm{~h}$ in the dark.

\section{Comparison of catalytic ability}

The concentrations of each component were maintained throughout except where indicated. In a quartz cuvette $(10 \mathrm{~mm})$, DI water $(1 \mathrm{~mL})$, catalyst $(0.3 \mathrm{mM}, 1 \mathrm{~mL})$ and 4-nitrophenol stock solution $(30 \mu \mathrm{L})$ were mixed. Sodium borohydride stock solution $(50 \mu \mathrm{L})$ for 4-nitrophenol reduction was then added to the mixture, followed by a quick shake of the cuvette. The absorption spectra were then recorded on a SCINCO S-4100 Scan UV-visible spectrophotometer at room temperature.

The reduction was visualized by the disappearance of the 400 $\mathrm{nm}$ peak of 4-nitrophenol and the appearance of a new peak at $300 \mathrm{~nm}$ for 4-aminophenol. We observed the kinetics of the

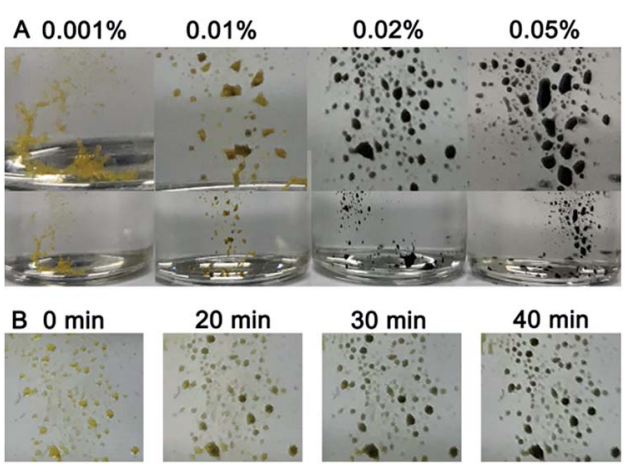

Fig. 6 Detection of water content in toluene with lyophilised gold suprananoparticles. (A) Photos of the suprananoparticles 60 min after they were immersed in toluene in the presence of $0.001 \%, 0.01 \%$, $0.02 \%$ and $0.05 \%$ of water. The upper row shows magnified images of the samples in the lower row. (B) Photos of the sample in (A) $(0.02 \%)$ taken in situ, $20 \mathrm{~min}, 30 \mathrm{~min}$ and $40 \mathrm{~min}$ after immersion in toluene. reaction by recording the change in the absorbance of the 4nitrophenolate ions at $400 \mathrm{~nm}$.

\section{Size distribution of nanoparticles}

The diameter of the nanoparticles in the TEM/SEM images was measured with ImageJ, in which a line was drawn across the distance of interest and Analyze/Measure was applied. The "length" in the result report was the diameter of the gold nanoparticles. The diameters of the gold nanoparticles and suprananoparticles in the TEM/SEM images were respectively measured randomly. At least 500 suprananoparticles were processed.

\section{Detection of water content in organic solvents}

A glass vial containing the freeze-dried gold nanoparticles was filled with organic solvents with known water contents. The cap of the vial was then closed tightly.

\section{Conclusions}

In summary, nanoparticles fused to form larger nanoparticles to form gold-wire networks and irregularly shaped plates, and further to form polygonal plates as the reducing capability of PEI decreased for the production of PEI-stabilized gold nanoparticles. However, as the reducing power of PEI was depleted at a PEI/Au molar ratio of $1: 40$, suprananoparticles consisting of ultra-small gold nanoparticles were generated. The low level of elemental gold and the stabilization of gold nanoparticles by the excess gold ions contributed to the production of ultra-small nearly neutral gold nanoparticles whereas the cross-linking between gold ions/PEI/nanoparticles further led to the assembly of these small gold nanoparticles into suprananoparticles that were stable in water. The suprananoparticles showed excellent catalytic activity for the reduction of 4-nitrophenol, suggesting that substrates could permeate through the suprananoparticle network. Such suprananoparticles could be stored stably in a dry place after lyophilisation. The hygroscopic $\mathrm{Au}(\mathrm{III})$ residues in the suprananoparticle solid absorbed moisture to form a micro-water pool and subsequently the nanoparticles in the new aqueous solution reshuffled to larger nanoparticles, leading to a colour change of the solid from yellow to black. We formulated the material into a fast, sensitive and straightforward tool to detect the water content in organic solvents. Our results indicated that ionic precursors may play an important role in the formation and stabilization of nanoparticles. Moreover, the ionic residues, regardless of whether they are a part of the nanostructure or impurities, may introduce further characteristics and significantly change the properties of the nanostructure.

\section{Conflicts of interest}

There are no conflicts to declare. 


\section{Acknowledgements}

This work was supported by the Korean National Research Foundation (2015R1A2A1A15055721 and 2018R1D1A1B07050171). S. Choi thanks NRF (2015R1D1A1A01057710 and 2018R1D1A1B07046393).

\section{Notes and references}

1 M. L. Personick and C. A. Mirkin, J. Am. Chem. Soc., 2013, 135, 18238-18247.

2 M. Rycenga, C. M. Cobley, J. Zeng, W. Li, C. H. Moran, Q. Zhang, D. Qin and Y. Xia, Chem. Rev., 2011, 111, 36693712 .

3 Y. Xia, T. D. Nguyen, M. Yang, B. Lee, A. Santos, P. Podsiadlo, Z. Tang, S. C. Glotzer and N. A. Kotov, Nat. Nanotechnol., 2011, 6, 580.

4 M. C. Daniel and D. Astruc, Chem. Rev., 2004, 104, 293-346.

5 J. Turkevich, P. C. Stevenson and J. Hillier, Discuss. Faraday Soc., 1951, 11, 55-75.

6 M. Brust, M. Walker, D. Bethell, D. J. Schiffrin and R. Whyman, J. Chem. Soc., Chem. Commun., 1994, 801-802, DOI: $10.1039 / \mathrm{c} 39940000801$.

7 X. Sun, S. Dong and E. Wang, J. Colloid Interface Sci., 2005, 288, 301-303.

8 M. Thomas and A. M. Klibanov, Proc. Natl. Acad. Sci. U. S. A., 2003, 100, 9138-9143.

9 F. S. Mohammed, S. R. Cole and C. L. Kitchens, ACS Sustainable Chem. Eng., 2013, 1, 826-832.

10 Y. Liu, K. B. Male, P. Bouvrette and J. H. T. Luong, Chem. Mater., 2003, 15, 4172-4180.

11 V. Subramanian, E. E. Wolf and P. V. Kamat, J. Am. Chem. Soc., 2004, 126, 4943-4950.

12 H. C. Haas, N. W. Schuler and R. L. Macdonald, J. Polym. Sci., Part A: Polym. Chem., 1972, 10, 3143-3158.

13 C. M. Aikens, J. Phys. Chem. C, 2008, 112, 19797-19800.

14 E. Rabani, D. R. Reichman, P. L. Geissler and L. E. Brus, Nature, 2003, 426, 271-274.

15 Y. Yao, M. Xue, Z. Zhang, M. Zhang, Y. Wang and F. Huang, Chem. Sci., 2013, 4, 3667-3672.
16 C.-L. Chen, P. Zhang and N. L. Rosi, J. Am. Chem. Soc., 2008, 130, 13555-13557.

17 S. Choi, Y. Jeong and J. Yu, RSC Adv., 2016, 6, 73805-73809.

18 S. Choi, Y. Jeong and J. Yu, Catal. Commun., 2016, 84, 80-84.

19 K. A. Curtis, D. Miller, P. Millard, S. Basu, F. Horkay and P. L. Chandran, PLoS One, 2016, 11, e0158147.

20 F. Kretschmer, U. Mansfeld, S. Hoeppener, M. D. Hager and U. S. Schubert, Chem. Commun., 2014, 50, 88-90.

21 A. Henglein, Chem. Rev., 1989, 89, 1861-1873.

22 H. Al-Johani, E. Abou-Hamad, A. Jedidi, C. M. Widdifield, J. Viger-Gravel, S. S. Sangaru, D. Gajan, D. H. Anjum, S. Ould-Chikh, M. N. Hedhili, A. Gurinov, M. J. Kelly, M. El Eter, L. Cavallo, L. Emsley and J.-M. Basset, Nat. Chem., 2017, 9, 890.

23 T. Rajský and M. Urban, J. Phys. Chem. A, 2016, 120, 39383949.

24 H. G. Boyen, G. Kastle, F. Weigl, B. Koslowski, C. Dietrich, P. Ziemann, J. P. Spatz, S. Riethmuller, C. Hartmann, M. Moller, G. Schmid, M. G. Garnier and P. Oelhafen, Science, 2002, 297, 1533-1536.

25 A. Villa, N. Dimitratos, C. E. Chan-Thaw, C. Hammond, G. M. Veith, D. Wang, M. Manzoli, L. Prati and G. J. Hutchings, Chem. Soc. Rev., 2016, 45, 4953-4994.

26 S. Peters, S. Peredkov, M. Neeb, W. Eberhardt and M. AlHada, Surf. Sci., 2013, 608, 129-134.

27 G. Ertas, U. Korcan Demirok and S. Suzer, Appl. Surf. Sci., 2005, 249, 12-15.

28 F. Opekar and P. Tůma, Sens. Actuators, B, 2015, 220, 485490.

29 H. Sun, B. Wang and S. G. DiMagno, Org. Lett., 2008, 10, 4413-4416.

30 L. Ding, Z. Zhang, X. Li and J. Su, Chem. Commun., 2013, 49, 7319-7321.

31 C. Dumas and C. C. Hsu, J. Chromatogr. A, 1982, 240, 508514.

32 Y. Hui, E. L. K. Chng, C. Y. L. Chng, H. L. Poh and R. D. Webster, J. Am. Chem. Soc., 2009, 131, 1523-1534. 